Check for updates

Cite this: Mater. Adv., 2021,

2. 1284

\section{Elaboration and mechanical properties of elastomeric fibrous scaffolds based on crosslinked poly(glycerol sebacate) and cyclodextrin for soft tissue engineering $\dagger$}

\author{
Florence Flaig, Caroline Faria Bellani, Özgün Uyumaz, Guy Schlatter (D)* and \\ Anne Hébraud (D) *
}

Poly(glycerol sebacate) (PGS) is a promising material designed for soft tissue engineering. Several examples of its use to prepare electrospun scaffolds can be found in the literature. However, the fabrication of nanofibrous scaffolds based on crosslinked PGS remains challenging because of its thermoset nature. Here, we propose a new method to electrospin PGS in blend with polyvinylpyrrolidone (PVP) and hydroxypropyl- $\beta$-cyclodextrin (HP $\beta C D$ ) as carrier molecules. After electrospinning, the PGS prepolymers were crosslinked by thermal treatment under vacuum, resulting in elastomeric fibers. Finally, unreacted molecules were removed by immersion of the fibers in water. Our PGS/HPBCD-based nanofibrous scaffolds are good candidates for soft tissue engineering with a Young's modulus of $2 \mathrm{MPa}$ and strain at break of $390 \%$ in the dry state, reaching 120 to $170 \mathrm{kPa}$ and $70 \%$ in the wet state.
Received 3rd September 2020 Accepted 29th December 2020 DOI: 10.1039/d0ma00673d

rsc.li/materials-advances scaffold in a nanofibrous mat, mimicking the extracellular matrix, can also be achieved by electrospinning and has shown to enhance tissue regeneration. ${ }^{7}$ Electrospun scaffolds have thus become promising candidates for tissue engineering. ${ }^{7-10}$

However, as PGS is an insoluble thermoset elastomer, it is not possible to electrospin it directly. Thus, PGS scaffolds have to be prepared in at least 3 steps. In the first step, the polycondensation of glycerol and sebacic acid leads to a soluble low-molar mass prepolymer (pPGS). In the second step, pPGS should be melted or dissolved in order to process it by electrospinning. Finally, a curing step at $120-180{ }^{\circ} \mathrm{C}$ under vacuum allows the crosslinking of pPGS into a $3 \mathrm{D}$ macromolecular elastomeric network.

However, because of its low molar mass, pPGS does not provide entanglements in solution, which is necessary to prevent the breaking of the jet into droplets during electrospinning. ${ }^{11}$ Different carrier polymers able to provide entanglements have thus been added into the pPGS solution to produce continuous nanofibers by electrospinning. As examples, proteins such as zein, gelatin or collagen were used for their good biocompatibility. Zein ${ }^{12}$ or gelatin ${ }^{13,14}$ was blended with pPGS to prepare fibers with up to two thirds of pPGS in the case of gelatin, while collagen was used as the shell material in the coaxial electrospinning of core-shell fibers containing pPGS in the core. ${ }^{15}$ In both cases, pPGS was not crosslinked into the PGS elastomer because proteins are not heat resistant and the mats cannot therefore withstand thermal treatment. To reach relatively high strains, proteins were crosslinked with EDC/NHS solutions for 
gelatin ${ }^{13}$ or under glutaraldehyde vapors for collagen. ${ }^{15}$ However, an additional toxicity is brought by these reactants, whereas the final material does not benefit from PGS elastomeric properties. Several works also focused on electrospinning of pPGS blended with the thermoplastic poly( $\varepsilon$-caprolactone) (PCL) to prepare cardiac patches, ${ }^{16,17}$ but in this case too, no curing step is possible due to the low melting temperature of the carrier polymer $\left(\begin{array}{ll}60 & \\ & \end{array}\right)$. Electrospinning of pPGS blended with poly(lactic acid) (PLA) was also carried out for heart tissue engineering applications. ${ }^{18,19}$ However, although these scaffolds achieved excellent biological properties, PLA was not removed and the overall mechanical properties were not elastomeric. As a matter of fact, the chosen carrier polymer should have a glass transition temperature $\left(T_{\mathrm{g}}\right)$ or melting temperature $\left(T_{\mathrm{m}}\right)$ higher than the curing temperature in order to maintain the shape of the fibers and prevent the low-viscosity melted pPGS from leaking out of the fibers during crosslinking. Moreover, after crosslinking, it should be possible to dissolve the carrier polymer to obtain pure crosslinked PGS fibers. In this context, You et al. ${ }^{20,21}$ used PLA as the carrier polymer in coaxial electrospinning. They electrospun a core solution of pPGS and a shell solution of PLA $\left(T_{\mathrm{m}}=160^{\circ} \mathrm{C}\right)$. Polyethylene oxide $\left(\mathrm{PEO}, T_{\mathrm{m}}=60^{\circ} \mathrm{C}\right)$ was added to the shell in order to decrease the modulus of the final material. The PEO had to be removed by dissolution in water before curing at $120^{\circ} \mathrm{C}$, and PLA was removed by dissolution in chloroform after crosslinking. The resultant fibrous mat had a Young's modulus of $0.47 \mathrm{MPa}$ in the dry state which is suitable for soft tissues. However, in this method, a toxic solvent is employed to purify the PGS fibers: a water-soluble carrier polymer would be a better choice. Poly(vinyl alcohol) (PVA) was chosen by $\mathrm{Xu}$ et $\mathrm{al}^{22}$ to electrospin coaxial fibers with PVA as the shell and pPGS as the core. After crosslinking, the PVA was partially removed by dissolution in water, leading to a material having a Young's modulus close to $35 \mathrm{MPa}$ and a strain at break of $130 \%$ in the wet state. The blend strategy was preferred by Jeffries $e t a l^{23}$ whose work led, after curing and dissolution of PVA in water, to fibrous mats having, in the wet state, a Young's modulus close to $1 \mathrm{MPa}$ and strain at break potentially higher than $750 \%$ under the weakest crosslinking conditions. Nevertheless, in these last examples, it was not possible to entirely remove the carrier polymer. This could be explained by a chemical reaction occurring during curing between the alcohols on PVA and the carboxylic acids on PGS.

In the present study, polyvinylpyrrolidone (PVP) was chosen as the carrier polymer for blend electrospinning as it has a $T_{\mathrm{g}}$ of $180{ }^{\circ} \mathrm{C}$ allowing thermal post-treatments, is water soluble and presents no reactive sites for PGS. Moreover, it is approved by the FDA for biomedical applications. PVP was also used with PPGS in blend electrospinning by Keirouz et $a l^{24}$ to prepare fibers with up to $40 \%$ pPGS. But in this work, PGS was not totally crosslinked in the thermoset elastomer. Yet, uncrosslinked pPGS is known to possibly induce toxicity due to the acid groups. ${ }^{25}$

In our work, in order to increase the content of PGS in the fibers while preventing the fibers to merge together during electrospinning or crosslinking, addition of hydroxypropyl- $\beta$ cyclodextrin (HP $\beta C D$ ) in the processed mixture was proposed.
Indeed, $\mathrm{HP} \beta \mathrm{CD}$ has a high degradation temperature $\left(278^{\circ} \mathrm{C}\right)$, is biocompatible and is known to have the ability to stabilize the electrospinning process. ${ }^{26-28}$ Besides, its hydrophobic cavity can be exploited to encapsulate drugs by host-guest inclusion complexes. ${ }^{29}$ Different blends of pPGS, PVP and HP $\beta C D$ were electrospun to form materials with $50 \%$ of pPGS and various proportions of PVP and HP $\beta C D$. The minimal HP $\beta C D$ content necessary to electrospin regular fibers in a stable way was identified. These fibers were cured following two different heating settings in order to tune their mechanical properties. Finally, they were washed in water to remove the PVP and unreacted $\mathrm{HP} \beta C D$ and obtain elastomeric mats. Their mechanical properties were compared to those of PGS-based scaffolds prepared with PVA as the carrier polymer in order to evaluate their suitability for soft tissue engineering.

\section{Experimental}

\section{Materials}

Glycerol (>99.96\%, Fisher Chemicals), sebacic acid (98\%, Acros Organics), d-DMSO (99.8\%D, Euriso-top), polyvinylpyrrolidone (PVP, $1300 \mathrm{~kg} \mathrm{~mol}{ }^{-1}$, Aldrich), hydroxypropyl- $\beta$ cyclodextrin (HPßCD, 97\%, degree of substitution: 2 to 6, Acros Organics), dimethylformamide (DMF, $>99.8 \%$, Sigma-Aldrich), absolute anhydrous ethanol ( $>99.9 \%$, Carlo Erba) and 1,1,1,3,3,3-hexafluoro-2-propanol (HFIP, >99.0\%, TCI Chemicals) were used as received. Poly(vinyl alcohol) (PVA, Gohsenol ${ }^{\mathbb{R}}$ EG-05PW, saponification value 86.5-89.0 mol\%) was generously donated by Nippon Gohsei ${ }^{\mathrm{TM}}$ and used as received.

\section{Synthesis and characterization of the prepolymer (PPGS)}

PGS synthesis was adapted from previous procedures. ${ }^{30,31}$ Briefly, $6.987 \mathrm{~g}$ (75.9 mmol, 2 equivalents) of glycerol, $23.013 \mathrm{~g}$ (113.9 mmol, 3 equivalents) of sebacic acid and a stirrer bar were introduced into a $100 \mathrm{~mL}$ round-bottomed flask. An open glass extender tube was connected to the flask to let the water vapor leave the reactor. The flask was placed in a microwave oven (Discover SP, CEM) and heated at $150{ }^{\circ} \mathrm{C}$ with a maximal power of $200 \mathrm{~W}$. The reaction was stopped before complete crosslinking of PGS, otherwise neither the dissolution nor the subsequent process could be envisaged. After 400 minutes at $150{ }^{\circ} \mathrm{C}$, a pale-yellow liquid is obtained. After cooling to room temperature, pPGS was pasty. The flask was placed under vacuum for $1 \mathrm{~h}$ at room temperature to evaporate excess of water without important loss of potential remaining glycerol. The sample was taken for ${ }^{1} \mathrm{H}$ NMR $(400 \mathrm{MHz}$, Bruker) analysis in d-DMSO. The degree of esterification was calculated from NMR analysis (Fig. S1, ESI $\dagger$ ) according to the following equation:

$$
\mathrm{DE}=\frac{\text { number of esters created }}{\text { number of } \mathrm{COOH} \text { inital }} \times 100=\frac{I_{\text {esters }}}{I_{\text {esters }}+I_{\text {acids }}} \times 100
$$

with $I_{\text {acids }}$ and $I_{\text {esters }}$ are the integration of the peaks on the spectra obtained by ${ }^{1} \mathrm{H}$ NMR, respectively at $2.18 \mathrm{ppm}$ for the carboxylic acids $\left(-\mathrm{CH}_{2}-\mathrm{COOH}\right)$ and $2.28 \mathrm{ppm}$ for the esters $\left(-\mathrm{CH}_{2}-\mathrm{COOR}\right)$. The prepolymer used for the electrospinning process had a DE of $72 \%$. 
Electrospinning of pPGS/HPßCD/PVP blends and optimization

pPGS, PVP and HPßCD are all soluble in DMF and ethanol. Electrospinning solutions were thus prepared $24 \mathrm{~h}$ prior to electrospinning, by dissolving the three components in DMF/ ethanol $3 / 7$ to reach $13 \mathrm{wt} \%$ of total solid in the solution.

This total solid content was composed of $50 \%$ of pPGS, $X \%$ of $\operatorname{HP} \beta C D(X=0,5,10,15,20$ or 25$)$ and $(50-X) \%$ of PVP. The compositions of the solutions are summarized in Table 1. Samples are named CDX with $X$ being the percentage of HPßCD in the solid expressed in percentage of weight by weight of solid. A home-made vertical electrospinning set-up including a cylindrical rotating collector, covered by backing paper, and translating needles was used. Two metallic 18 gauge needles were fed with a solution at $2.4 \mathrm{~mL} \mathrm{~h}^{-1}$ by using a syringe pump (PHD 2000, Harvard Apparatus). The collector was placed $15 \mathrm{~cm}$ above the tip of the needles and rotated at $150 \mathrm{rpm}$. High voltage was applied to the collector $(-5 \mathrm{kV})$ and to the needles $(14 \mathrm{kV})$ by two power supplies (SL10, Spellman). Large membranes $\left(15 \times 30 \mathrm{~cm}^{2}\right)$ suitable for post-treatments were electrospun for $5 \mathrm{~h}$.

\section{Electrospinning of pPGS/PVA blends}

Fibrous mats with $50 \mathrm{wt} \%$ of pPGS and $50 \mathrm{wt} \%$ of PVA were prepared by blend electrospinning using HFIP as the solvent. The solution, containing $3.2 \mathrm{wt} \%$ of pPGS and $3.2 \mathrm{wt} \%$ of PVA in HFIP, was prepared $24 \mathrm{~h}$ prior to electrospinning. The same electrospinning set-up was used as for pPGS/HP $\beta C D / P V P$ samples. The distance between the needles and the collector was fixed at $18 \mathrm{~cm}$ and the applied voltage was $25 \mathrm{kV}$ at the needles and $-1 \mathrm{kV}$ at the collector. The solution was infused at $2.0 \mathrm{~mL} \mathrm{~h}^{-1}$ in each syringe. Because of its low stability, the process was stopped after $1 \mathrm{~h}$ but it was enough to obtain detachable and easy to handle samples. All other parameters were kept the same as for $\mathrm{pPGS} / \mathrm{HP} \beta \mathrm{CD} / \mathrm{PVP}$. These samples containing $50 \%$ of PVA were named PVA50.

\section{Crosslinking of PGS and purification of the fibers}

After peeling from the paper, the samples were cut into appropriate shapes and placed between two frames tightened together by clamps to limit membrane shrinkage during curing. They were put in a pre-heated vacuum oven (Vacutherm VT6025, Fisher Scientific) at $120{ }^{\circ} \mathrm{C}$. The curing step was then conducted under a pressure below $10^{-2}$ mbar following different curing schemes: a short one with a maximal reached temperature of $140{ }^{\circ} \mathrm{C}$ named $\mathrm{C}_{\text {short }}\left(24 \mathrm{~h}\right.$ at $120{ }^{\circ} \mathrm{C}$ followed by $48 \mathrm{~h}$ at $140{ }^{\circ} \mathrm{C}$ ) and a long one with a maximal temperature of $170{ }^{\circ} \mathrm{C}$

Table 1 Composition of electrospinning solutions in DMF/ethanol 3/7 (w/w). All percentages are expressed as weight of solid over total weight of solution

\begin{tabular}{llll}
\hline Sample name & pPGS (\%) & HPßCD (\%) & PVP (\%) \\
\hline CD0 & 6.5 & 0 & 6.5 \\
CD5 & 6.5 & 0.65 & 5.85 \\
CD10 & 6.5 & 1.3 & 5.2 \\
CD15 & 6.5 & 1.95 & 4.55 \\
CD20 & 6.5 & 2.6 & 3.9 \\
CD25 & 6.5 & 3.25 & 3.25
\end{tabular}

named $\mathrm{C}_{\text {long }}\left(24 \mathrm{~h}\right.$ at $120{ }^{\circ} \mathrm{C}$ followed by $48 \mathrm{~h}$ at $140{ }^{\circ} \mathrm{C}$ and $24 \mathrm{~h}$ at $\left.170{ }^{\circ} \mathrm{C}\right)$.

After curing, the CD25 and PVA50 samples were immersed in gently stirred osmosed water. After $1 \mathrm{~h}, 2 \mathrm{~h} 30$ minutes and $19 \mathrm{~h}$ of immersion, the water was changed and the membranes were rinsed. After $24 \mathrm{~h}$ of washing, they were dried overnight under vacuum at ambient temperature.

\section{Characterization of PGS-based mats}

The surface of the samples was observed by scanning electron microscopy (SEM) after coating with a thin layer of gold. The SEM (Vega 3, Tescan) was used in high vacuum mode with a voltage of $5 \mathrm{kV}$. The mean diameter of fibers was calculated over 100 diameter measurements using Image J software. The mean values are given with the standard deviation.

The efficiency of the mat purification was first evaluated by measuring the mass loss after washing. Attenuated Total Reflectance-Fourier Transform Infrared (ATR-FTIR) spectroscopy analyses were also performed (Nicolet 380, Thermo Fisher) before and after washing to characterize the PVP and PVA removal. Results were compared with raw materials' spectra.

The mechanical properties in the dry state of the as-spun, cured, and washed mats were determined by uniaxial tensile tests using the linear tension geometry of a rheometer (Discovery HR3, TA Instruments). Rectangular samples were cut with $5 \mathrm{~mm}$ width and about $20 \mathrm{~mm}$ long. The purified samples were also characterized in the wet state after two days of immersion in osmosed water. The width and thickness were then measured after hydration. The samples were fixed in the clamps with an initial gap of $10 \mathrm{~mm}$ and then pre-loaded with an axial force of about $0.01 \mathrm{~N}$. The gap after preloading was set as the initial length. The tensile tests were conducted at $150 \mu \mathrm{m} \mathrm{s}^{-1}$ until breaking. 5 measurements were performed for each type of sample. The Young's modulus was calculated as the slope of the curve in the initial (between 0 and $1 \%$ of deformation) linear part.

Cyclic tests were conducted on cured and washed samples at dry and wet states to evaluate elastic recovery. Specimens were cut and their dimensions were measured in the same way as that for tensile tests. After pre-loading, they were stretched at $150 \mu \mathrm{m} \mathrm{s}^{-1}$ until a strain of $15 \%, 15 \%$ elongation being a typical value for cardiac muscles. ${ }^{32,33}$ After stretching, the samples were released at the same rate until $0 \%$ elongation to conclude one cycle, and a new cycle was started. The loading-release cycle was repeated 10 times.

\section{Results and discussion}

In the strategy presented here, fibrous scaffolds are prepared by blend electrospinning of pPGS with either PVP and HP $\beta$ CD or PVA followed by a crosslinking and a washing step (Fig. 1A). A pPGS prepolymer was first synthetized, with a degree of esterification (DE) equal to $72 \%$ prepared with a molar ratio glycerol/sebacic acid fixed at 2/3, corresponding to the stoichiometric ratio (Fig. 1B). 
A

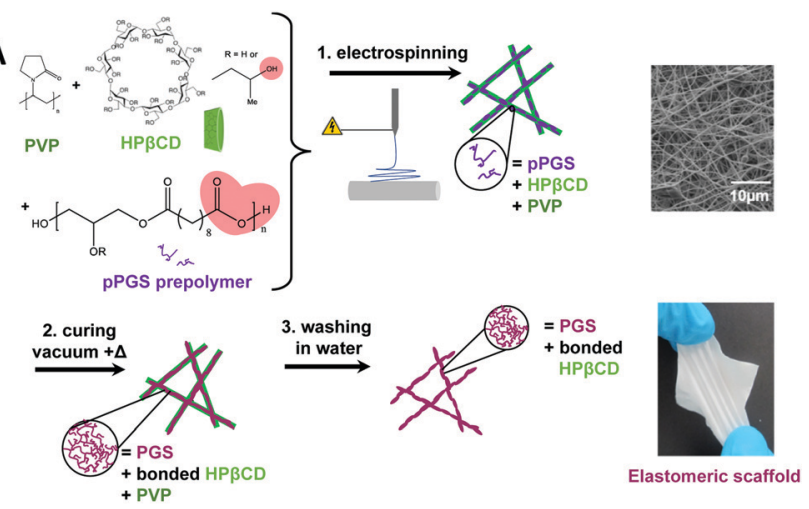

B

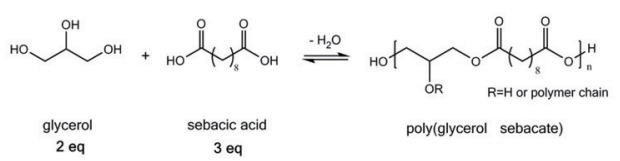

Fig. 1 Strategy for the elaboration of the elastomeric PGS-based fibers During thermal treatment, pPGS is crosslinked and reaction of $-\mathrm{OH}$ groups of $\mathrm{HPBCD}$ with $-\mathrm{COOH}$ groups of pPGS (in red) occurs (A). Chemical scheme of pPGS synthesis by polycondensation of glycerol and sebacic acid (B).

This ratio, favoring the reaction of the glycerol secondary alcohol during crosslinking, combined with a high DE, leads to a pPGS very close to its gel point. It results in a fast crosslinking of PGS, leaving no time for the pPGS to flow outside of the fibers during thermal treatment.

pPGS was then electrospun with the carrier material. Preliminary experiments have shown that PVP alone is not a good carrier for PGS as it does not allow maintaining the fibrous structure of the scaffold during thermal treatment (Fig. S2 and S3, ESI $\dagger$ ). HP $\beta C D$, with a high degradation temperature $\left(278{ }^{\circ} \mathrm{C}\right)$, is thus required to maintain the fibrous structure during curing and to stabilize the electrospinning process.

\section{Effect of cyclodextrin and PVP contents on the fiber morphology}

In order to prepare elastomeric mats and investigate their properties depending on the crosslinking parameters, the material content in the PGS/PVP/HP $\beta C D$ fibers was first optimized. Consistent with the literature,${ }^{23}$ the amount of pPGS in the as-spun dry fibers was fixed at $50 \%$. Indeed, a high enough percentage of pPGS is required to have continuous fibers after curing and washing, and a sufficient amount of carrier polymer is needed to retain the fiber shape during thermal treatment. The objective was thus to find a formulation able to reach an amount of $50 \%$ of pPGS with the help of PVP and HP $\beta C D$ as carrier materials while preserving the fibrous morphology of the final scaffold.

Electrospinning of formulations with less than $1.95 \%$ of HP $\beta C D$ in the solution (CD15) was not stable due to periodic breaking of the jet (several times a minute) leading to solution projections on the collector. It did not allow the formation of continuous fibers, as shown for CD0 in Fig. 2. For CD5 and CD10, fibers could be seen on the collector but they tended to stick together and form an almost continuous film
(Fig. S4, ESI $\dagger$ ). PVP alone was not able to stabilize the jet and form solid enough fibers with such a high proportion of pPGS. A minimum of $15 \%$ of $H P \beta C D$ was necessary to obtain membranes made of continuous fibers. Moreover, an increase of the HP $\beta C D$ content combined with a decrease of PVP content resulted in a slight decrease of the fiber diameters, from $511 \pm 136 \mathrm{~nm}$ for CD15, $382 \pm 144 \mathrm{~nm}$ for CD20 to $318 \pm$ $143 \mathrm{~nm}$ for CD25, the decrease of the carrier polymer quantity leading to a lower solution viscosity.

These materials were cured to crosslink the PGS. Fig. 2 shows that $15 \%$ of $\mathrm{HP} \beta C D$ was not enough to avoid the melting of the fibers. Finally, with $20 \%$ of HP $\beta C D$ and more, it was possible to obtain fibers with crosslinked PGS and only few melted areas, mostly at the contact points between fibers and around the few beads.

\section{Fabrication of elastomeric mats}

In this work, the mechanical properties of the mats prepared from $\mathrm{pPGS} / \mathrm{HP} \beta \mathrm{CD} / \mathrm{PVP}$ and $\mathrm{pPGS} / \mathrm{PVA}$ blends are compared with an identical pPGS weight amount of $50 \%$. For the strategy based on the use of HP $\beta C D$ and PVP, contents of $25 \mathrm{wt} \%$ of HP $\beta C D$ and $25 \mathrm{wt} \%$ of PVP were taken. This condition, with a solid content of $13 \%$, allows the fabrication of regular fibers as shown above. Moreover, it was assumed that a higher content in cyclodextrin would increase the modulus of the final materials as HP $\beta C D$ can create multiple crosslinking points due to its large number of $-\mathrm{OH}$ groups. The selected formulation led to the fabrication of thin fibers (CD25 having a mean diameter of $318 \pm 143 \mathrm{~nm}$ ) comprising some beads (Fig. 3). In the case of 50/50 pPGS/PVA fibers, regular fibers were obtained from solutions containing a total concentration of solid of $6.4 \mathrm{wt} \%$, while other values did not allow the formation of continuous fibers. It led to regular fibers being almost 5 times thicker than CD25 (PVA50 mean diameter: $1402 \pm 503 \mathrm{~nm}$, Fig. 3B). CD25 fibers are less regular, but in any case, the fiber morphology is more or less modified by the curing step. In addition, the preparation of PVA50 fibers requires the use of a costly and toxic solvent, HFIP, which is not the case for CD25.

The mats were then crosslinked under vacuum following two different heating settings: $\mathrm{C}_{\text {short }}\left(24 \mathrm{~h}\right.$ at $120^{\circ} \mathrm{C}$ followed by $48 \mathrm{~h}$ at $\left.140{ }^{\circ} \mathrm{C}\right)$ or $\mathrm{C}_{\text {long }}\left(24 \mathrm{~h}\right.$ at $120^{\circ} \mathrm{C}$ followed by $48 \mathrm{~h}$ at $140{ }^{\circ} \mathrm{C}$ and $24 \mathrm{~h}$ at $170{ }^{\circ} \mathrm{C}$ ). The influence of the curing parameters on the morphology and the mechanical properties of the final scaffolds was investigated. After curing, the crosslinked PGS/ $\mathrm{HP} \beta \mathrm{CD} / \mathrm{PVP}$ fibers are fused together at the contact points and some melted spots are also visible. Fig. 3 shows the result after $\mathrm{C}_{\text {long, }}$, but the same observations can be noted after $\mathrm{C}_{\text {short }}$ curing conditions (Fig. 2 and Fig. S5, ESI $\dagger$ ). The integrity of the PVA/ PGS fibers is better preserved after curing, even if fibers are also merged at contact points.

After the washing step in water, cured CD25 partially lost their fibrous morphology (Fig. 3A). In particular, numerous continuous areas are observed on cured CD25 crosslinked under $\mathrm{C}_{\text {short }}$ conditions, leading to a high density of less porous areas. Under $\mathrm{C}_{\text {long }}$ crosslinking conditions, a higher porosity is observed. From these results, it can be concluded that if PGS is 
CDO
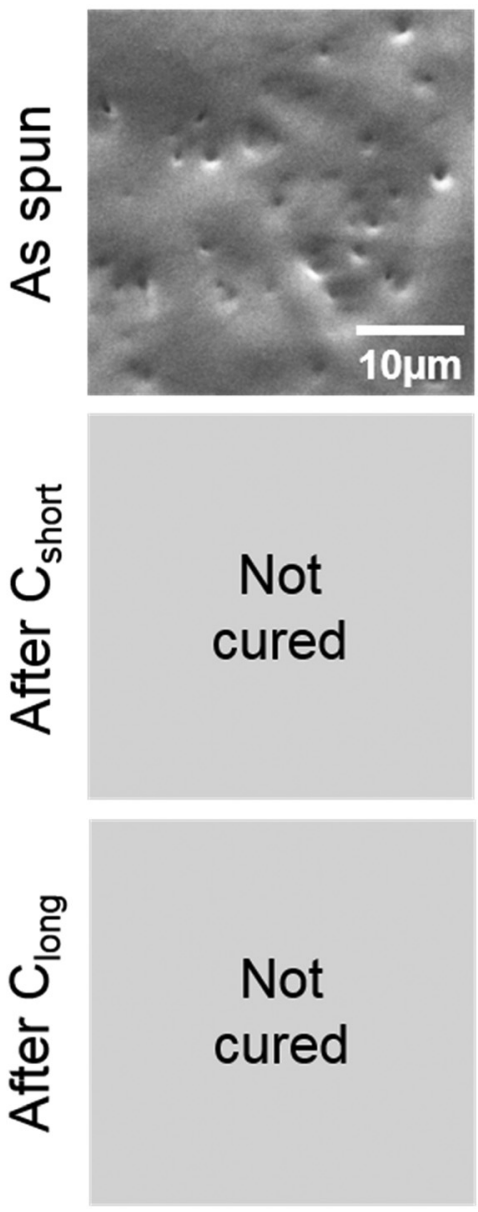

CD15
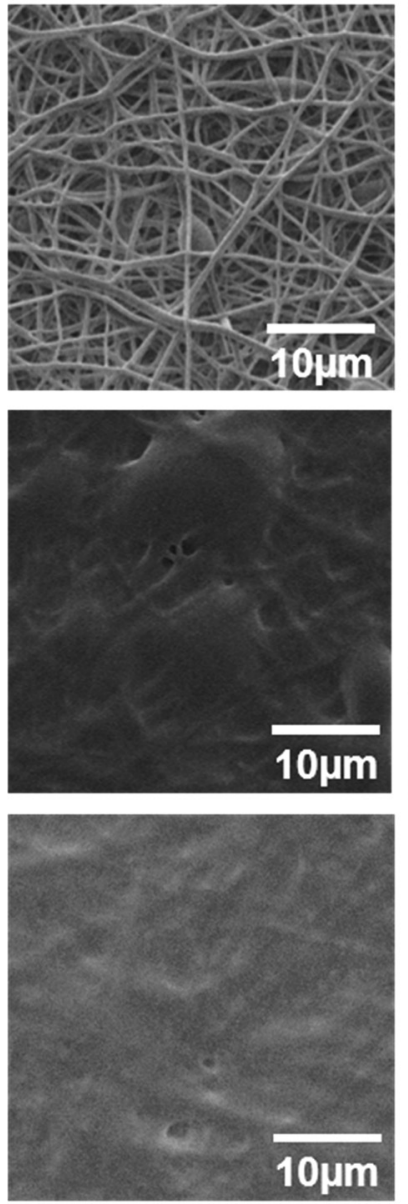

CD20
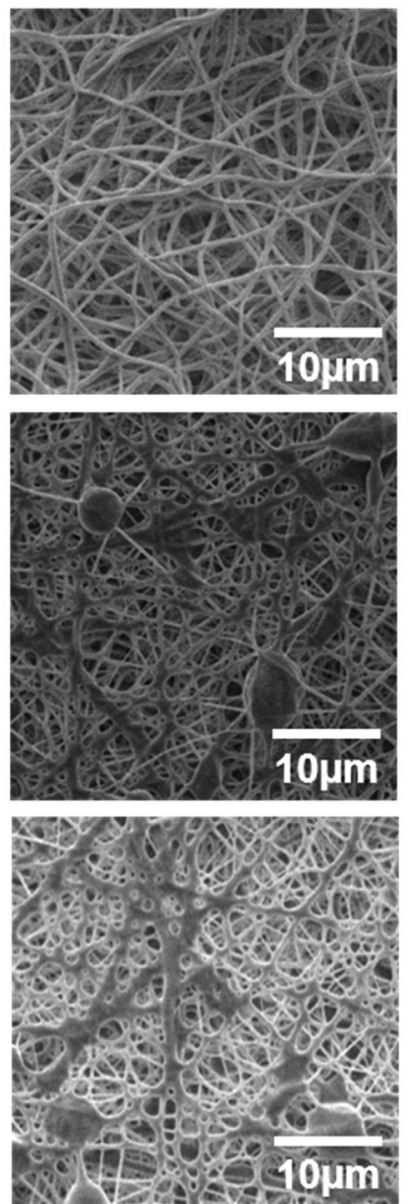

CD25
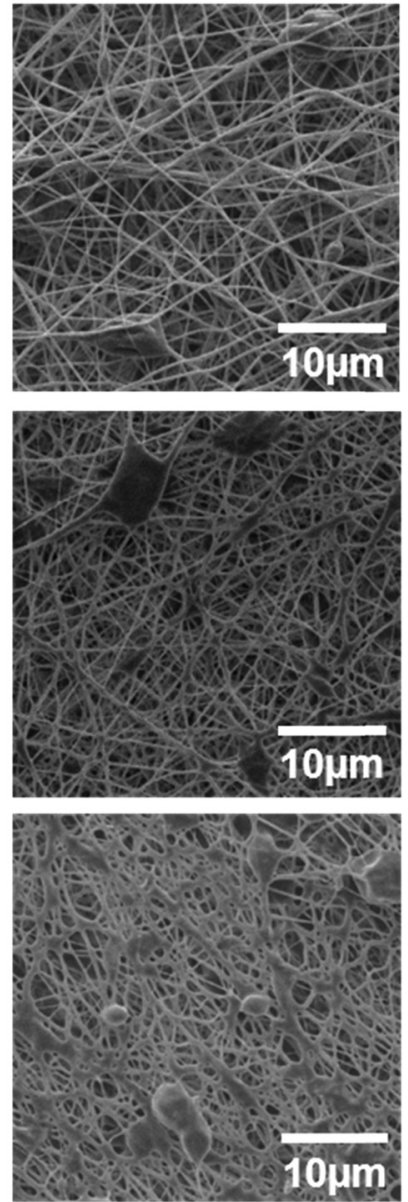

Fig. 2 Influence of the proportion of HP $\beta C D$ on the PGS/HP $\beta C D / P V P$ fiber morphology before and after curing for various formulations. CDO contains $50 \%$ of PGS and $50 \%$ of PVP; CD15 contains $50 \%$ of PGS, $15 \%$ of HP $\beta C D$ and $35 \%$ of PVP; CD20 contains $50 \%$ of PGS, $20 \%$ of HP $\beta C D$ and $30 \%$ of PVP. The morphology is shown after the following curing steps: $24 \mathrm{~h}$ at $120{ }^{\circ} \mathrm{C}$ followed by $48 \mathrm{~h}$ at $140{ }^{\circ} \mathrm{C}\left(\mathrm{C}_{\text {short }}\right.$ ) or $24 \mathrm{~h}$ at $120{ }^{\circ} \mathrm{C}, 48 \mathrm{~h}$ at $140{ }^{\circ} \mathrm{C}$ and $24 \mathrm{~h}$ at $170{ }^{\circ} \mathrm{C}$ ( ( long).

not enough crosslinked, some of the material can be dissolved or swollen out of the fibers and redeposit around them. In the case of washed crosslinked PVA50 fibers, the fibrous structure is well preserved thanks to the fact that the PVA50 fiber diameter is much larger than that of CD25 fibers (Fig. 3B). This result can also be justified by strong interactions between PGS and PVA as -OH groups of PVA can react with - $\mathrm{COOH}$ groups of PGS. Yet, cured PVA50 fibers are slightly attached together by melted materials too. Besides, it can be observed that PVA left a noticeable roughness or even small pores at the surface of the fibers after its removal (Fig. 3C).

In order to check the efficiency of the washing step, the membranes were weighed before and after washing and drying. In all cases, $65 \%$ to $80 \%$ of the initial mass remains after washing showing that pure PGS membranes are not obtained. However, the removal seems to be more efficient after the $\mathrm{C}_{\text {short }}$ curing than after $\mathrm{C}_{\text {long: }}$ : $68 \%$ of $\mathrm{CD} 25-\mathrm{C}_{\text {short }}$ remains after washing versus $72 \%$ for $\mathrm{CD} 25-\mathrm{C}_{\text {long. }}$. The same tendency is observed in the case of PVA50: 75\% of the initial weight remains after washing for
PVA50- $\mathrm{C}_{\text {short }}$ whereas a percentage of $78 \%$ is measured for PVA50$\mathrm{C}_{\text {long. }}$. Thus, the $\mathrm{C}_{\text {long }}$ procedure leads to more "entrapment" of the carrier material in the fiber matrix. This "entrapment" can be the effect of covalent bonding, especially between PVA or HP $\beta C D$ and PGS, or the effect of an entanglement of the carrier polymer (PVA for PVA50 or PVP for CD25) in the PGS network, both effects being increased for a higher reaction time or temperature and the resulting higher crosslinking density. It can be noted that the removal is more efficient for CD25 than for PVA50, demonstrating stronger interactions between PVA and PGS.

In order to obtain more insight into the efficiency of the fiber washing step, ATR-FTIR characterization was carried out. The spectra of cured CD25 and cured PVA50 before and after washing were compared to pPGS, PVP, HP $\beta C D$ (Fig. 4A-C and Fig. S6, S7, ESI $\dagger$ ) and PVA spectra (Fig. 4D-F and Fig. S8, S9, ESI $\dagger$ ). Two areas of interest are considered. In the first one, corresponding to the elongation of $\mathrm{C}=\mathrm{O}$ bonds $\left(1650-1730 \mathrm{~cm}^{-1}\right)$, the pPGS spectrum shows characteristic bands for acids at $1710 \mathrm{~cm}^{-1}$ and for esters at $1730 \mathrm{~cm}^{-1}$. In the fibers after curing, the shoulder 


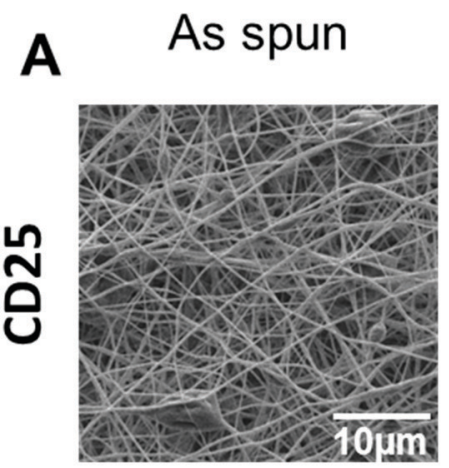

After $\mathrm{C}_{\text {long }}$
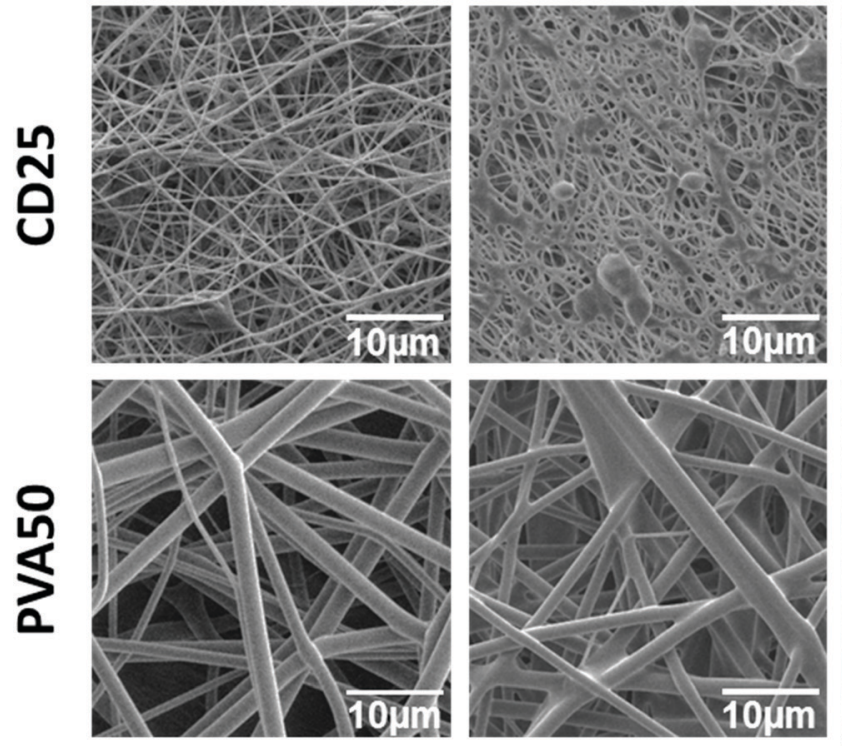

B

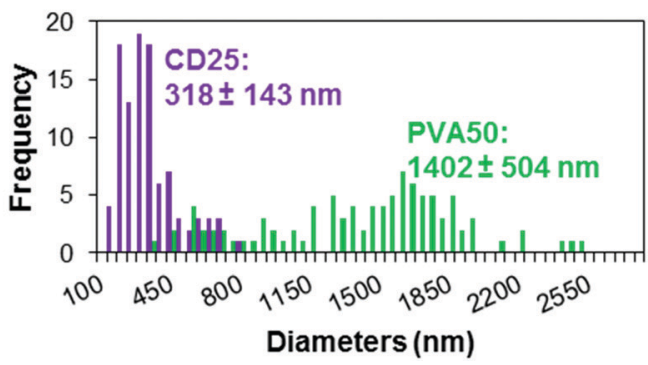

After $\mathrm{C}_{\text {long }}$ and washing
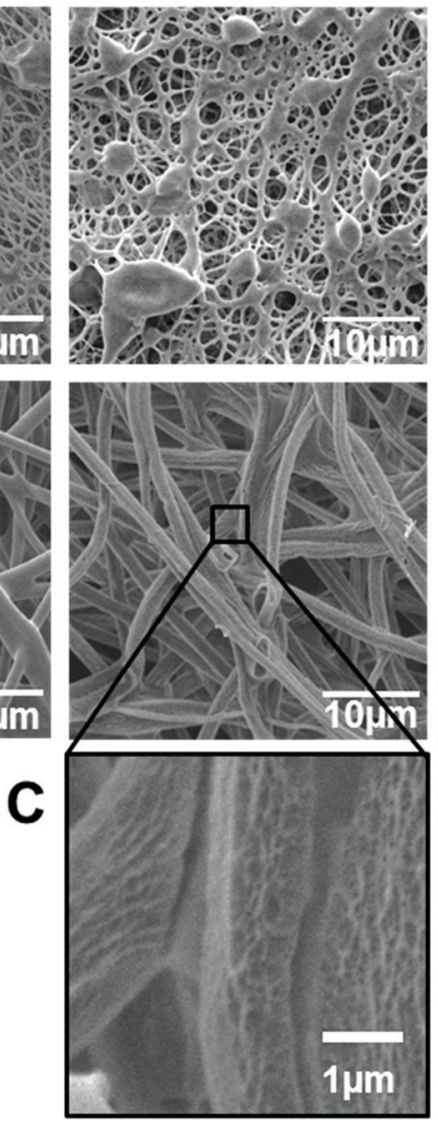

After $\mathrm{C}_{\text {short }}$ and washing
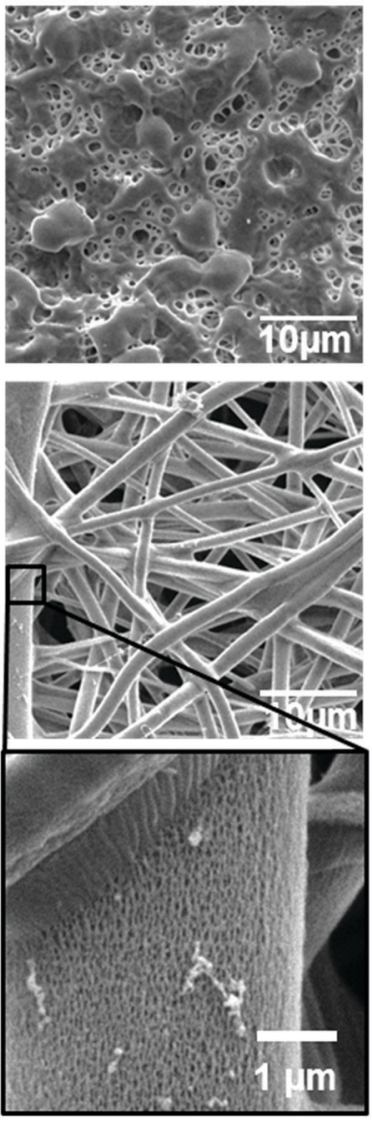

Fig. 3 Morphology of the fibers as spun and after post-treatments. Low magnification SEM pictures (A), diameter distribution of diameters of as-spun fibers (B) and high magnification pictures of cured PVA50-washed fibers (C). CD25 contains 50\% of PGS, 25\% of HP $\beta C D$ and $25 \%$ of PVP; PVA contains $50 \%$ of PGS and $50 \%$ of PVA. The morphology is shown here after $\mathrm{C}_{\text {long }}\left(24 \mathrm{~h}\right.$ at $120^{\circ} \mathrm{C}, 48 \mathrm{~h}$ at $140{ }^{\circ} \mathrm{C}$ and $24 \mathrm{~h}$ at $\left.170{ }^{\circ} \mathrm{C}\right)$ and after $24 \mathrm{~h}$ washing in water.

at $1710 \mathrm{~cm}^{-1}$ is not visible anymore (Fig. 4B), confirming the esterification. The PGS characteristic bands partially overlap the PVP band arising from the amide $\mathrm{C}=\mathrm{O}$ bond $\left(1650 \mathrm{~cm}^{-1}\right)$ in the CD25 sample (Fig. 4B). In the same way, the $\mathrm{C}=\mathrm{O}$ band of residual acetate groups of PVA $\left(1724 \mathrm{~cm}^{-1}\right)$ is overlapped with the $\mathrm{C}=\mathrm{O}$ bands of PGS in PVA50 (Fig. $4 \mathrm{E}$ ). The second interesting area includes the $\mathrm{C}-\mathrm{O}$ of esters bonds $\left(1160 \mathrm{~cm}^{-1}\right), \mathrm{C}-\mathrm{O}$ in $\mathrm{HP} \beta \mathrm{CD}$ $\left(1027 \mathrm{~cm}^{-1}\right), \mathrm{C}-\mathrm{N}$ in PVP $\left(1287 \mathrm{~cm}^{-1}\right)$ and $\mathrm{C}-\mathrm{C}$ in PVA $\left(845 \mathrm{~cm}^{-1}\right)$. Because of the overlapping of the bands, it was difficult to quantify the presence of each component, but the evolution of intensities was investigated. In $\mathrm{CD} 25-\mathrm{C}_{\text {long }}$, the intensity of the band at $1027 \mathrm{~cm}^{-1}$ clearly decreases relatively to PGS bands after washing (Fig. 4C). Indeed, the ratio of intensities of $\mathrm{C}-\mathrm{O}$ in $\mathrm{HP} \beta \mathrm{CD}$ over $\mathrm{C}-\mathrm{O}$ in PGS decreases from 1.2 before washing to 0.7 after washing, showing that cyclodextrin was partially lost during the washing step. However, the PVP band at $1287 \mathrm{~cm}^{-1}$ does not clearly decrease relatively to PGS band: the ratio of intensities remains stable at 0.6. Surprisingly, it seems that HP $\beta C D$ was easier to wash away, despite the fact that cyclodextrin can be covalently bonded with PGS. Indeed, all HPßCD molecules are not bonded to PGS, because there are 3 to 4 times more $-\mathrm{OH}$ groups (primary and secondary alcohols) from cyclodextrin than $-\mathrm{COOH}$ groups from PGS. Moreover, it can be assumed that the long PVP macromolecules are actually trapped in the PGS network. In PVA50, the band at $845 \mathrm{~cm}^{-1}$ decreased relatively to PGS band after washing (Fig. 4F): the ratio of intensities of C-C from PVA over C-O from PGS decreased from 0.7 to 0.4. This result highlights the partial removal of the PVA. The remaining PVA is bonded to the PGS or trapped in the network too.

Mechanical properties. The objective of this work was to prepare a scaffold with mechanical properties matching soft tissue properties, especially the myocardium's one. It was shown that the left ventricular stiffness is about $10-20 \mathrm{kPa}$ at the beginning of diastole and is in the range of $200-500 \mathrm{kPa}$ at the end of diastole. ${ }^{4}$ Tensile tests were thus conducted to determine if the PGS-based membranes are suitable regarding such specifications. The effect of the curing and of the washing was evaluated, as well as the nature of the carrier material. Typical stress-strain curves are shown in Fig. 5A (all curves are given in Fig. S10 and S11, ESI $\dagger)$. The mean Young's moduli $(E)$, strain at break $\left(\varepsilon_{\text {break }}\right)$ and ultimate tensile stress (UTS) are given in Fig. 5B. 

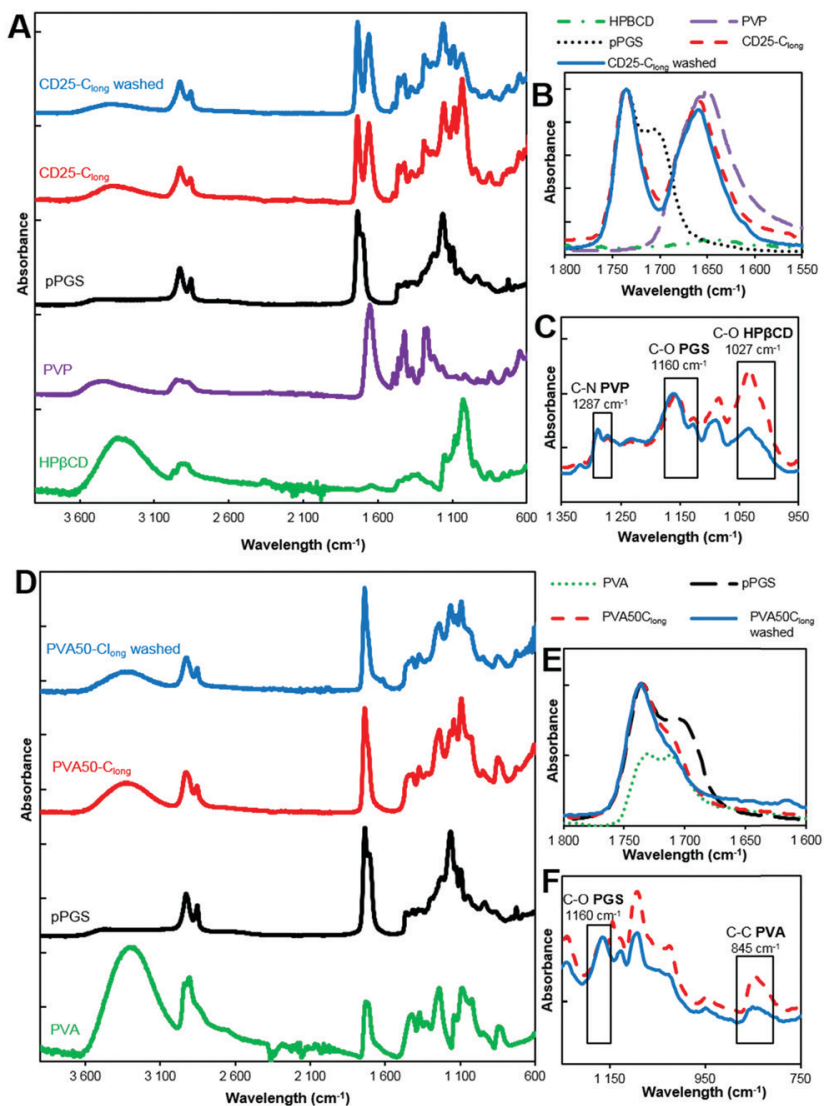

Fig. 4 ATR-FTIR spectra of CD25 (A-C) and PVA50 (D and E) after curing and after purification compared to HP $\beta C D, P V P, P V A$ and corresponding pPGS spectra. ( $A$ and $D$ ) Full spectra. ( $B$ and $E$ ) $C=O$ bands, absorbance normalized to the $1730 \mathrm{~cm}^{-1}$ band. ( $\mathrm{C}$ and F) $\mathrm{C}-\mathrm{O}, \mathrm{C}-\mathrm{C}$ and $\mathrm{C}-\mathrm{N}$ bands, absorbance normalized to the $1160 \mathrm{~cm}^{-1}$ band.

The comparison of the results of the as-spun and cured samples clearly shows that the curing step increases the modulus and the stress at break. Two explanations can be given about this observation. First, the curing step leads to the crosslinked elastomer network which obviously enhances the overall strength. However, the maximal strain is not significantly improved by cross-linking because heating the fibers leads to their fusion at the contact points and therefore to strong bonding between them. The relative movement of fibers along each other is thus inhibited, which is a reason for the increase of the modulus and UTS.

The washing step decreases the Young's modulus and increases the strain at break. This result highlights the fact that the rigid carrier materials were at least partially removed, allowing the elastomer to have more impact on the overall mechanical properties of the scaffolds. After washing, it can be seen that the longest curing step leads to a higher modulus and UTS and lower strain at break. Indeed, $\mathrm{C}_{\text {long }}$ pushes further the reaction to a higher crosslinking density. Moreover, it has been shown by weighing that the rigid carrier materials are less efficiently washed away after $\mathrm{C}_{\text {long }}$ than after $\mathrm{C}_{\text {short }}$ curing step, what could also explain the modulus increase.
In addition, it should be noted that cured and washed PVA50 and CD25 have different mechanical behaviors. PVA50 stress-strain curves show a clear first elastic domain with high modulus, before a region of irreversible deformations with lower modulus until breaking at higher strains. For cured and washed CD25, the first high modulus-domain is drastically reduced, and almost invisible. This difference can be explained by the structure and composition of the mats. PVA50 and CD25 can be compared to point-bonded PVC/TPU-based structures described by Lee et al. ${ }^{34}$ PVA50 still contains a large amount of rigid PVA but the density of bonding between its fibers is low; this case corresponds to fibers with a high PVC/TPU ratio. When the mat is stretched, these bonds hinder the slipping of the fibers, while the PVA phase endures the load until a critical stress is reached. Then, the elastomeric PGS phase governs the behavior. CD25 samples are more similar to PVC/TPU fibers with high TPU content with the density of bonding points being very high.

Moreover, it can be considered that the PGS content is higher because it was shown that the mass loss after washing is higher for CD25 than for PVA50. In addition to that, a fraction of the remaining carrier material of CD25 is cyclodextrin, which is included in the elastomeric network as crosslink points and influences the elastomeric behavior. So, the mat is a quasicontinuous elastomeric phase, and behaves almost as such.

The values given in Fig. 5B indicate that PVA50 has a higher modulus and UTS than CD25 regardless of the post-treatments. After curing and washing, PVA50 has a Young's modulus higher than $50 \mathrm{MPa}$ for a strain at break close to $150 \%$ and an UTS close to $5 \mathrm{MPa}$. The washed CD25- $\mathrm{C}_{\text {short }}$ and $\mathrm{C}_{\text {long }}$ have Young's moduli of 2 and $6 \mathrm{MPa}$ respectively and UTS below $2 \mathrm{MPa}$. After washing, the average strain at break reached $390 \%$ for $\mathrm{C}_{\text {short }}$ and $111 \%$ for $\mathrm{C}_{\mathrm{long}}$. In summary, the use of PVA as the carrier polymer leads to stiffer materials than in the case of the use of $\mathrm{HP} \beta \mathrm{CD}$ and PVP.

From Fig. 5, it can be noted that most of the samples do not show a linear elastic behavior for strains higher than $3 \%$. Cyclic mechanical tests were thus conducted to study how the materials recover after several cycles of deformation. Fig. 6 represents some typical stress-strain curves obtained with samples over 3 cycles of deformation varying from 0 to $15 \%$. The maximal strain value of $15 \%$ was chosen to mimic the strain underwent by the heart tissue. ${ }^{32}$

For all samples, during the first cycle, the stretching part of the curve is very different from the releasing part of the curve. But after the first deformation and release, all the following cycles overlap. This is visible in Fig. 6 for cycles 2 and 3 (10 cycles can be seen for all samples in Fig. S12 and S13, ESI $\dagger$ ). This overlapping illustrates a lower loss of energy than after the first cycle, suggesting that the membranes underwent an irreversible deformation during this first stretching-release. This can be justified be the relative movement of the fibers along each other.

The energy recovery after stretching and release back to $0 \%$ of strain was calculated as the ratio of the area under the stressstrain curve during release over the area under the curve during 

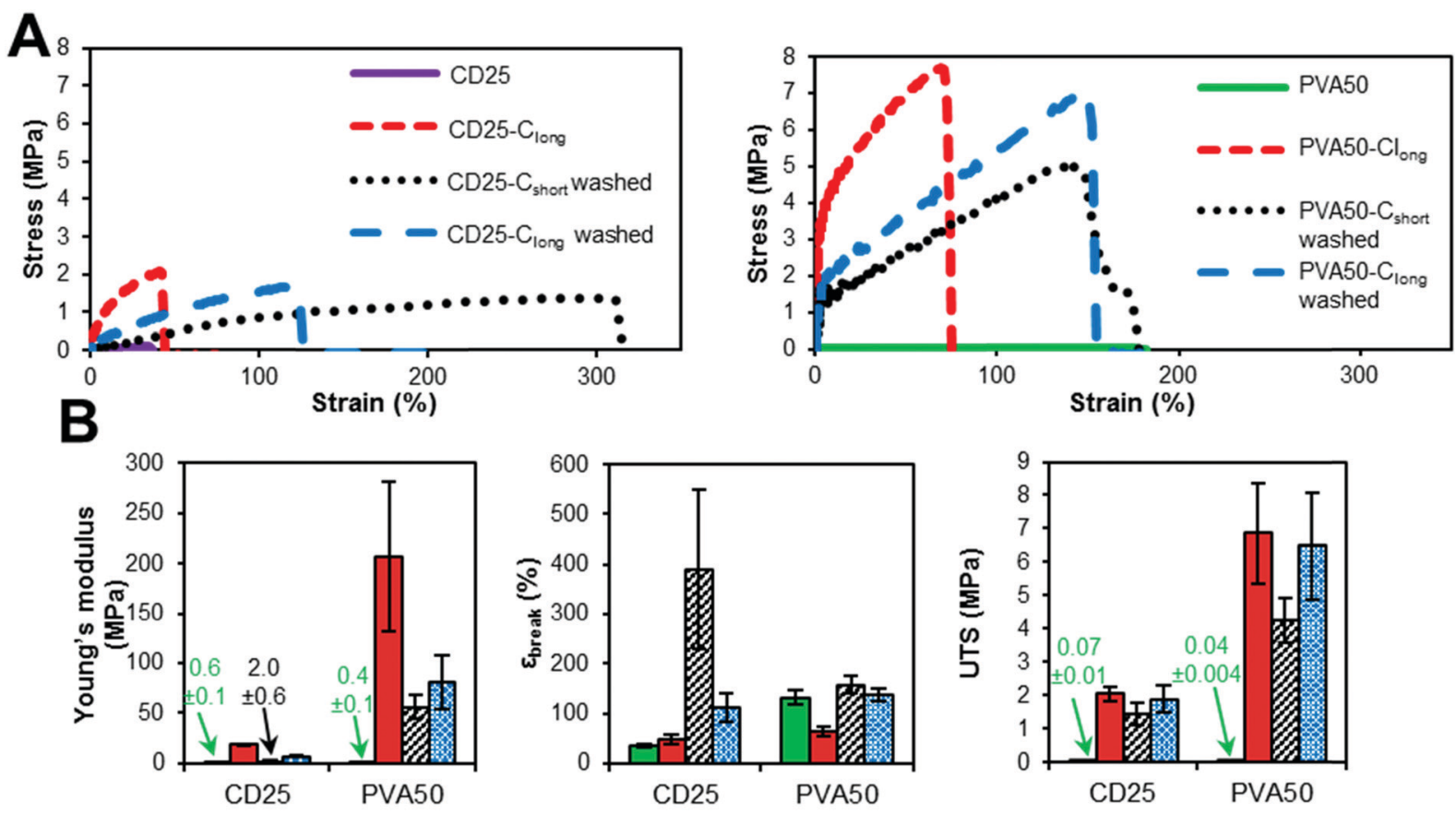

口As spun

a $\mathrm{C}_{\text {short }}$ washed

घ. $\mathrm{C}_{\text {long }}$ washed

Fig. 5 Influence of curing and washing on the mechanical properties of CD25 and PVA50. (A) Typical stress-strain curves. (B) Evolution of modulus, strain at break and UTS along curing and washing.
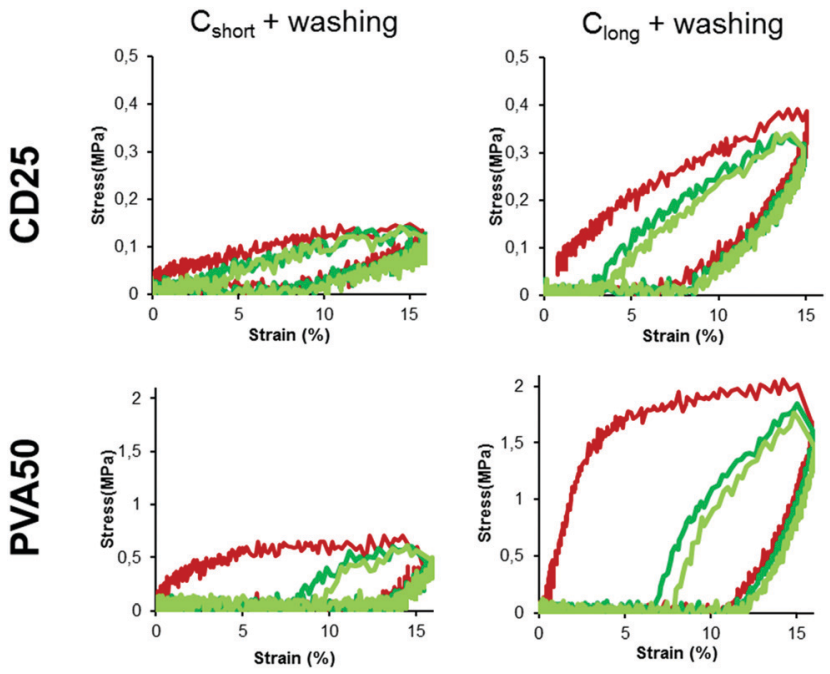

Cycle 1 Cycle 2 Cycle 3

Fig. 6 Stress-strain curves obtained for cured and washed CD25 and PVA50 between 0 and $15 \%$ of strain for the three first cycles.

stretching. The calculated values confirm the poor recovery during the first cycle (Fig. 7 in grey). PVA50 recovery is close to $10 \%$ after $\mathrm{C}_{\text {short }}$ and $\mathrm{C}_{\text {long }}$ whereas the recovery of CD25 is slightly higher with values above $20 \%$. An average value was calculated for cycle 2 to 10 as they are similar. The recovery reaches then nearly $40 \%$ for CD25 and $50 \%$ for PVA50 for samples after $\mathrm{C}_{\text {short }}$. After $\mathrm{C}_{\text {long }}$, the recovery is worse for PVA50 with $33 \%$ but stable for CD25.

Finally, both materials show similar behavior under repeated cycles except during the first extension of the material: PVA50 underwent more important irreversible structural modifications. The morphology of the fibrous samples can help to justify this result. Indeed, as PVA50's fibers are better defined and include a lower density of fixed contact points, they can move with higher amplitudes, these displacements being permanent. In contrast, the washed $\mathrm{CD} 25-\mathrm{C}_{\text {short }}$ sample comprises a high density of fixed contact points and shows thus less irreversible deformations.

Mechanical properties were also measured on hydrated scaffolds (Fig. 8). The results show a clear decrease in modulus, UTS and strain at break for all samples after hydration. Indeed, the

$$
\mathrm{C}_{\text {short }}+\text { washing }
$$

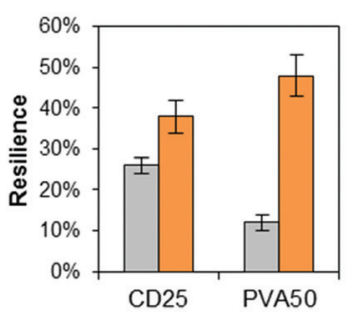

$\square$ Cycle 1 Cycles 2-10

Fig. 7 Energy recovery after the first cycle and mean energy recovery during cycles 2 to 10 . The given value is the average value for 3 samples with the standard deviation. 
Table 2 Mechanical properties of PGS containing fibrous scaffolds in dry or wet state

\begin{tabular}{|c|c|c|c|c|c|c|c|}
\hline Fiber composition (\%PGS) & $\begin{array}{l}\text { Electrospinning } \\
\text { solvent }\end{array}$ & $\begin{array}{l}\text { Carrier polymer } \\
\text { removal }\end{array}$ & $\begin{array}{l}\text { Elastic modulus } \\
\text { (MPa) }\end{array}$ & $\begin{array}{l}\text { Strain at } \\
\text { break (\%) }\end{array}$ & $\begin{array}{l}\text { UTS } \\
\text { (MPa) }\end{array}$ & State & Ref. \\
\hline pPGS/Zein (20\%) & Acetic acid & No & $6-14$ & $5-7$ & $0.3-13$ & Dry & 12 \\
\hline pPGS/gelatin (77\%) acrylate (UV) & HFIP & No & 10 & $20-40$ & 0.65 & Dry & 14 \\
\hline pPGS/gelatin (30-60\%) EDC-NHS & Acetic acid & No & $9-14$ & $31-34$ & $1.5-1.6$ & Dry & 13 \\
\hline pPGS/collagen (32\%) glutaraldehyde & HFIP & No & 4.2 & 84 & 2 & Dry & 15 \\
\hline PGS/gelatin (30-60\%) EDC-NHS & Acetic acid & No & $0.15-0.30$ & $90-180$ & 0.3 & Wet & 13 \\
\hline PGS/gelatin (77\%) acrylate (UV) & HFIP & No & $0.1-1$ & $30-45$ & 0.03 & Wet & 14 \\
\hline PGS/PVA $(>90 \%)$ & HFIP & Yes (water/ethanol) & $0.1-0.8$ & $200-750$ & $0.8-1.2$ & Wet & 23 \\
\hline PGS/PVA (>90\%) & HFIP & Yes (water) & 0.15 & 70 & 0.1 & Wet & This article \\
\hline PGS/HPßCD/PVP $(>90 \%)$ & DMF:ethanol & Yes (water) & $0.12-0.17$ & $50-70$ & $\begin{array}{l}0.08- \\
0.09\end{array}$ & Wet & This article \\
\hline
\end{tabular}

material swells in water and behaves as a hydrogel. It results in a wider elastic domain, the linear part reaching several tens of \%. For all samples, the moduli of hydrated scaffolds are close to 100-200 kPa (Fig. 8B), which is more suitable for soft tissue than the same dry samples. The maximal strains are lower than those in the dry state but still high enough for cardiac regeneration as the typical strain underwent by the heart tissue is $15 \%$. Cyclic tensile tests show the reversibility of the deformation in the elastic domain below 15\% (Fig. 8C).

Moreover, the mechanical properties in dry and wet states of our scaffolds were compared with those reported in the literature (Table 2). They fall in the same range as the other developed PGS containing fibers. What is important to note is that our
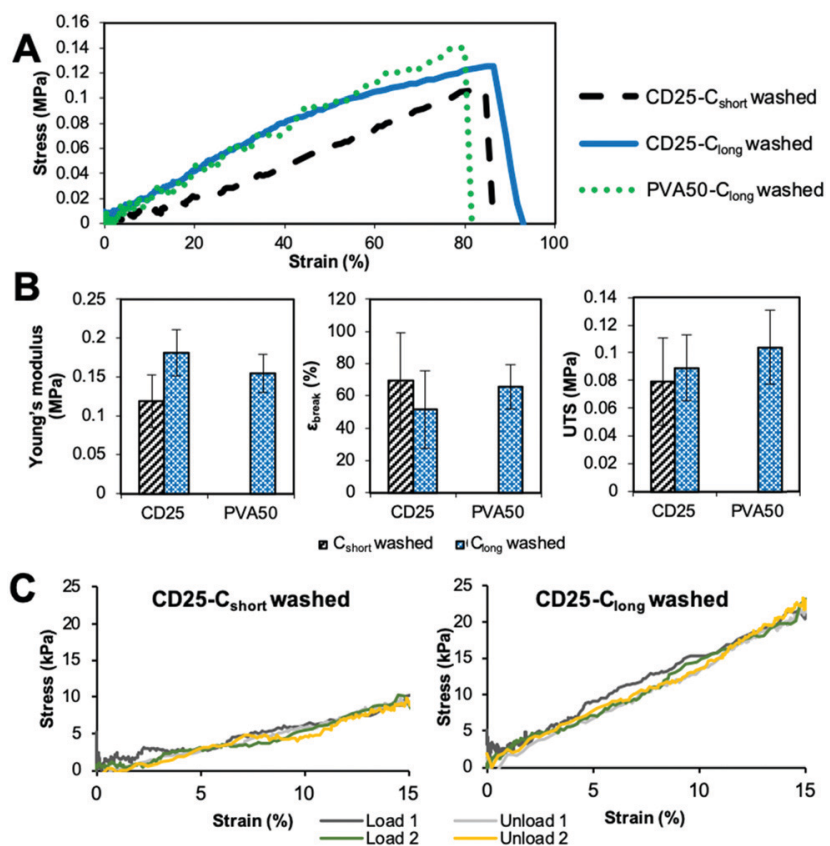

Fig. 8 Mechanical behavior of the scaffolds in the wet state. (A) Typical stress-strain curves, (B) evolution of modulus, strain at break and UTS with curing and washing. The given value is the average value for 3 samples with the standard deviation. (C) Stress-strain curves obtained for cured and washed CD25 samples between 0 and $15 \%$ strain.
PGS/HP $\beta C D / P V P$ system and the PGS/PVA one, first developed by Jeffries $e t$ al. ${ }^{23}$ are the only systems for which the pPGS is cured after electrospinning and the carrier polymer is washed, leaving almost pure PGS fibers, and without chemical crosslinking with toxic agents such as acrylate, EDC-NHS or glutaraldehyde.

\section{Conclusions}

In this work, PGS-based membranes were successfully prepared using a blend of PVP and HP $\beta C D$ as carrier molecules. Composite fibers with $50 \%$ of pPGS, $25 \%$ of PVP and $25 \%$ of HP $\beta \mathrm{CD}$ were electrospun, cured and washed. For comparison, fibers with $50 \%$ of pPGS and $50 \%$ of PVA were also electrospun and post-treated in the same way. The fibers obtained from pPGS/ PVP/HP $\beta C D$ are almost 5 times thinner than those obtained from PPGS/PVA. In both cases, the washing step did not lead to pure PGS fibers. Washing was however slightly more efficient for materials prepared with PVP and HP $\beta C D$. Mechanical characterization in the dry state showed that both types of membranes can be stretched at strains larger than $100 \%$ after washing but the moduli of $\mathrm{pPGS} / \mathrm{PVP} / \mathrm{HP} \beta \mathrm{CD}$ scaffolds are lower than those prepared with PVA. In addition, cyclic mechanical tests showed that samples prepared with PVP/HP $\beta C D$ have a good resilience, making them good candidates for soft tissue engineering. In the wet state, the moduli and tensile strength decrease, reaching values suitable for soft tissue engineering and the elastic domains increase allowing real elastic deformation of the scaffolds. Finally, the presence of cyclodextrin in the material should offer the possibility to encapsulate and deliver molecules of therapeutic interest.

\section{Conflicts of interest}

There are no conflicts to declare.

\section{Acknowledgements}

The authors acknowledge the financial support from the University of Strasbourg and CNRS. This work was supported by the 
Agence Nationale de la Recherche (MimHeart project ANR-15CE08-0010-02) CFB has received funding from the Fundação de Amparo à Pesquisa do Estado de São Paulo (FAPESP, process no. 2014/17939-0 and process no. 2016/04418-8) and by the Coordenação de Aperfeiçoamento de Pessoal de Nível Superior Brasil (CAPES) - Finance Code 001. The authors also thank Christophe Mélart for technical help.

\section{References}

1 Q.-Z. Chen, S. E. Harding, N. N. Ali, A. R. Lyon and A. R. Boccaccini, Materials Science and Engineering: $R$ : Reports, 2008, 59, 1-37.

2 A. J. Engler, S. Sen, H. L. Sweeney and D. E. Discher, Cell, 2006, 126, 677-689.

3 Y. Wang, G. A. Ameer, B. J. Sheppard and R. Langer, Nat. Biotechnol., 2002, 20, 602-606.

4 Q.-Z. Chen, A. Bismarck, U. Hansen, S. Junaid, M. Q. Tran, S. E. Harding, N. N. Ali and A. R. Boccaccini, Biomaterials, 2008, 29, 47-57.

5 Q.-Z. Chen, H. Ishii, G. A. Thouas, A. R. Lyon, J. S. Wright, J. J. Blaker, W. Chrzanowski, A. R. Boccaccini, N. N. Ali, J. C. Knowles and S. E. Harding, Biomaterials, 2010, 31, 3885-3893.

6 G. C. Engelmayr Jr, M. Cheng, C. J. Bettinger, J. T. Borenstein, R. Langer and L. E. Freed, Nat. Mater., 2008, 7, 1003-1010.

7 S. Sell, C. Barnes, M. Smith, M. McClure, P. Madurantakam, J. Grant, M. McManus and G. Bowlin, Polym. Int., 2007, 56, 1349-1360.

8 U. Boudriot, R. Dersch, A. Greiner and J. H. Wendorff, Artif. Organs, 2006, 30, 785-792.

9 J. Lannutti, D. Reneker, T. Ma, D. Tomasko and D. Farson, Mater. Sci. Eng., C, 2007, 27, 504-509.

10 S. Agarwal, J. H. Wendorff and A. Greiner, Adv. Mater., 2009, 21, 3343-3351.

11 F. Yi and D. A. LaVan, Macromol. Biosci., 2008, 8, 803-806.

12 D. Dippold, M. Tallawi, S. Tansaz, J. A. Roether and A. R. Boccaccini, Eur. Polym. J., 2016, 75, 504-513.

13 M. Kharaziha, M. Nikkhah, S.-R. Shin, N. Annabi, N. Masoumi, A. K. Gaharwar, G. Camci-Unal and A. Khademhosseini, Biomaterials, 2013, 34, 6355-6366.

14 J. L. Ifkovits, J. J. Devlin, G. Eng, T. P. Martens, G. VunjakNovakovic and J. A. Burdick, ACS Appl. Mater. Interfaces, 2009, 1, 1878-1886.
15 R. Ravichandran, J. R. Venugopal, S. Sundarrajan, S. Mukherjee and S. Ramakrishna, World J. Cardiol., 2013, 5, 28-41.

16 R. Rai, M. Tallawi, C. Frati, A. Falco, A. Gervasi, F. Quaini, J. A. Roether, T. Hochburger, D. W. Schubert, L. Seik, N. Barbani, L. Lazzeri, E. Rosellini and A. R. Boccaccini, Adv. Healthcare Mater., 2015, 4, 2012-2025.

17 M. Tallawi, D. Dippold, R. Rai, D. D’Atri, J. A. Roether, D. W. Schubert, E. Rosellini, F. B. Engel and A. R. Boccaccini, Mater. Sci. Eng., C, 2016, 69, 569-576.

18 F. Flaig, H. Ragot, A. Simon, G. Revet, M. Kitsara, L. Kitasato, A. Hébraud, O. Agbulut and G. Schlatter, ACS Biomater. Sci. Eng., 2020, 6, 2388-2400.

19 Y. Yan, V. Sencadas, T. Jin, X. Huang, J. Chen, D. Wei and Z. Jiang, J. Colloid Interface Sci., 2017, 508, 87-94.

20 Z.-R. You, M.-H. Hu, H.-Y. Tuan-Mu and J.-J. Hu, J. Mech. Behav. Biomed. Mater., 2016, 63, 220-231.

21 H.-J. Wu, M.-H. Hu, H.-Y. Tuan-Mu and J.-J. Hu, Mater. Sci. Eng., C, 2019, 100, 30-37.

22 B. Xu, Y. Li, C. Zhu, W. D. Cook, J. Forsythe and Q. Chen, Eur. Polym. J., 2015, 64, 79-92.

23 E. M. Jeffries, R. A. Allen, J. Gao, M. Pesce and Y. Wang, Acta Biomater., 2015, 18, 30-39.

24 A. Keirouz, G. Fortunato, M. Zhang, A. Callanan and N. Radacsi, Med. Eng. Phys., 2019, 71, 56-67.

25 Y. Li, W. D. Cook, C. Moorhoff, W.-C. Huang and Q.-Z. Chen, Polym. Int., 2012, 62, 534-547.

26 T. Uyar, A. Balan, L. Toppare and F. Besenbacher, Polymer, 2009, 50, 475-480.

27 F. Kayaci and T. Uyar, Carbohydr. Polym., 2012, 90, 558-568.

28 M. Séon-Lutz, A.-C. Couffin, S. Vignoud, G. Schlatter and A. Hébraud, Carbohydr. Polym., 2019, 207, 276-287.

29 F. J. Otero-Espinar, J. J. Torres-Labandeira, C. AlvarezLorenzo and J. Blanco-Méndez, J. Drug Delivery Sci. Technol., 2010, 20, 289-301.

30 X. Li, A. T.-L. Hong, N. Naskar and H.-J. Chung, Biomacromolecules, 2015, 16, 1525-1533.

31 G. Coativy, M. Misra and A. K. Mohanty, ACS Sustainable Chem. Eng., 2016, 4, 2142-2149.

32 C. Zhu, A. E. Rodda, V. X. Truong, Y. Shi, K. Zhou, J. M. Haynes, B. Wang, W. D. Cook and J. S. Forsythe, ACS Biomater. Sci. Eng., 2018, 4, 2494-2504.

33 A. I. Veress, G. T. Gullberg and J. A. Weiss, J. Biomech. Eng., 2005, 127, 1195-1207.

34 K. H. Lee, H. Y. Kim, Y. J. Ryu, K. W. Kim and S. W. Choi, J. Polym. Sci., Part B: Polym. Phys., 2003, 41, 1256-1262. 